\title{
David Oliver: Telehealth and telecare need a different approach
}

\author{
David Oliver consultant in geriatrics and acute general medicine
}

Berkshire

"Technology and innovation are key to saving the NHS," the former health secretary Alan Milburn wrote in the Observer. ${ }^{1}$ Milburn, who now chairs PricewaterhouseCoopers' Health Insight Industries Oversight Board, said that "the world is on the verge of a huge leap forward in healthcare, driven by advances in knowledge and technology ... an influx of new mobile and bio-devices will mean we will be able to check-and take greater control over-our health in a way never previously possible."

Milburn is hardly alone in this zeitgeist mantra, now repeated so often that it's become a new orthodoxy. Many health policy commentators, politicians, and management consultants are pushing digital remote healthcare, seemingly ecstatic at a brave new world with less need for trained healthcare practitioners or face-to-face human contact.

Private industry, not the NHS, is developing the technology, and this demands a potential return on costly upfront investment. The hands of marketers and lobbyists, including former NHS ministers or officials, are all over the rush towards "remote healthcare."

Private industry, not the NHS, is developing the technology, and this demands a potential return on costly upfront investment

Deploying these technologies makes sense for some patients in some circumstances. Anything that helps people remain at home with long term conditions, retain their independence, manage their own healthcare, or avoid acute admissions is worth trying-although new technologies should surely be subject to the same standard of empirical evidence as other interventions and service innovations.

Too often, however, the tail has wagged the dog. Look at the 2010-15 coalition government's " 3 Million Lives" project, which promised that this many people would benefit from remote healthcare. ${ }^{2}$ Where did this figure come from? It's not clear to me-though I note that a separate 2012 report, Remote Care $P L C$, set out a speculative, flimsy calculation full of heroic assumptions that arrived at this figure. ${ }^{3}$
Around the same time, government officials and Number 10's special adviser for health were plugging new technologies as a panacea. ${ }^{45}$ For instance, the Department of Health's Jim Easton (now of the private provider Care UK) wrote, "Telecare transforms lives, saves money and is backed by evidence. So what's stopping us?" $\mathrm{He}$ was referring to the large, government sponsored "Whole Systems Demonstrator" clinical trials of telehealth and telecare. ${ }^{7}$ Considering they'd been neither published nor peer reviewed at the time, this was disgraceful. Yet the Department of Health also published "headline findings" pushing the claims, well before peer review. ${ }^{8}$

Sadly, the results of the Whole Systems Demonstrator clinical trials were largely null in terms of the technology's effectiveness or cost effectiveness. ${ }^{910}$ It may still have tremendous potential. But why rush to premature conclusions?

In October 2017 a crucial review of the evidence passed largely under the medical community's radar: the Health Innovation Network's "Technology-Enabled Care Services" review is especially interesting because it was commissioned by NHS England. ${ }^{11}$ The 45 studies of video consultations it identified showed "no difference" across a whole range of indicators in patients with chronic physical illness. In remote telemonitoring it found decent evidence but only in people with diabetes, hypertension, heart disease, and COPD. In text messaging, 26 reviews had some evidence in glycaemic monitoring and substance misuse interventions. And, in health apps, the evidence across 25 reviews was inconclusive.

As Tim Burdsey concluded in the Health Service Journal, ${ }^{12}$ "There is limited evidence and the evidence for cost effectiveness is particularly scant." He added that "the evidence base hasn't caught up with the pace of innovation and technology."

I completely accept the second argument. The highly agile, fast moving tech industry and the NHS can seem like two cultures with separate languages and criteria for determining what works. But commercial companies (including private health providers or insurers) can invest in whatever technology suits them, 
whereas the NHS has an obligation to use scarce public money wisely and to base decisions on robust evidence.

Ideally, we want more randomised controlled trials of new technology. Failing that, let's at least have large, pragmatic quality improvement studies of the impact of telecare and telehealth on patient care and service delivery-with rigorous independent scrutiny, release of all data, and no commercial sponsorship or marketing speak. Integrity, transparency, and realism represent a better way to convince NHS sceptics than overoptimistic promises.

Competing interests: See www.bmj.com/about-bmj/freelancecontributors/david-oliver.

Provenance and peer review: Commissioned; not externally peer reviewed.

Follow David on Twitter: @mancunianmedic

1 Milburn A. Technology and innovation are key to saving the NHS. Guardian 22 Oct 2017 https://www.theguardian.com/commentisfree/2017/oct/22/technology-and-innovation-keyto-saving-the-nhs.

2 National Assembly of Wales, Health and Social Care Committee. Learning the lesson from 3 Million Lives.

www.senedd.assembly.wales/documents/s43139/MT\%20Al8\%20ADSS\%20Cymru.pdf.

3 Barlow J, Curry R, Chrysanthaki T, Hendy J, Taher N; Health and Care Infrastructure Research and Innovation Centre. Remote Care PLC: developing the capacity of the remote care industry to supply Britain's future needs. Nov 2012. www.haciric.org/static/ pdf/publications/HaCIRIC_Remote_Care_Report_061212.pdf.
4 Seddon N. Time for the NHS to import innovation[login required]. Health Serv J 2013;359. https://www.hsj.co.uk/comment/time-for-the-nhs-to-import-innovation/5056876.article.

5 Ayling M. Why innovation is a must-have-and how we drive it forward. Health Serv J 2013;359. https://www.hsj.co.uk/technology-and-innovation/why-innovation-is-a-musthave--and-how-we-drive-it-forward/5054808.article.

6 Easton J. Jim Easton: let's get serious about telehealth[login required]. Health Serv J 2012;359. https://www.hsj.co.uk/comment/jim-easton-lets-get-serious-about-telehealth/ 5046307.article.

7 Department of Health. NHS. Whole Systems Demonstrators: an overview of telecare and telehealth. http://webarchive.nationalarchives.gov.uk/20130104235033/http://www.dh. gov.uk/prod_consum_dh/groups/dh_digitalassets/documents/digitalasset/dh_100947.pdf.

8 Department of Health. Whole system demonstrator programme: headline findings—December 2011. 5 Dec 2011. https://www.gov.uk/government/news/wholesystem-demonstrator-programme-headline-findings-december-2011.

- Henderson C, Knapp M, Fernández J-L, et al. Whole System Demonstrator evaluation team. Cost effectiveness of telehealth for patients with long term conditions (Whole Systems Demonstrator telehealth questionnaire study): nested economic evaluation in a pragmatic, cluster randomised controlled trial. BMJ 2013;359:f1035. doi:10.1136/bmj. f1035 pmid:23520339.

10 Cartwright M, Hirani SP, Rixon L, et al. Whole Systems Demonstrator Evaluation Team Effect of telehealth on quality of life and psychological outcomes over 12 months (Whole Systems Demonstrator telehealth questionnaire study): nested study of patient reported outcomes in a pragmatic, cluster randomised controlled trial. BMJ 2013;359:f653. doi:10. 1136/bmj.f653 pmid:23444424.

11 Health Innovation Network. Technology-Enabled Care Services (TECS) evidence base review. 2017. https://healthinnovationnetwork.com/projects/tecs/.

12 Burdsey T. New technology solutions promise much-now can we work out which ones actually deliver?[login required]. Health Serv J2017;359. https://www.hsj.co.uk/technologyand-innovation/new-technology-solutions-promise-much--now-can-we-work-out-whichones-actually-deliver/7020731.article.

Published by the BMJ Publishing Group Limited. For permission to use (where not already granted under a licence) please go to http://group.bmj.com/group/rights-licensing/ permissions 